\title{
Prevalence of masked hypertension among children with risk factors for arterial hypertension
}

\author{
Adriana Iturzaeta, M.D. ${ }^{a}$, Luis Pompozzi, M.D. ${ }^{b}$, Claudia Casas Rey, B.S. ${ }^{b}$, \\ Irma Passarelli, M.D. ${ }^{a}$ and Fernando Torres, M.D. ${ }^{a}$
}

\section{ABSTRACT}

Introduction. Masked hypertension (MH) in children is defined as normal office blood pressure values and high values outside the clinical setting. The 24-hour ambulatory blood pressure monitoring (ABPM) is helpful for diagnosis. There is little information on $\mathrm{MH}$ prevalence in our population.

Objective. To estimate the prevalence of $\mathrm{MH}$ in children with risk factors for arterial hypertension.

a. Hospital General de Niños "Pedro de Elizalde".

b. Hospital de Niños "Dr. J. P. Garrahan." Autonomous City of Buenos Aires.

E-mail address:

Adriana Iturzaeta,

M.D.: aiturzaeta@

yahoo.com.ar

Funding:

This study was conducted with the support of the "Ramón CarrilloArturo Oñativia" scholarship program, individual category, granted by the National Ministry of Health of Argentina through the National Health Research Committee (Comisión Nacional Salud Investiga). Year 2015. National Registry of Health Research (Registro Nacional de Investigaciones en Salud, RENIS), Argentine Integrated Health Care Information System (Sistema Integrado de Información Sanitaria Argentino, SISA): health research code no. IS000927.

Conflict of interest:

None.

Received: 11-28-2017

Accepted: 4-16-2018

To cite: Iturzaeta A, Pompozzi L, Casas Rey C, et al. Prevalence of masked hypertension among children with risk factors for arterial hypertension. Arch Argent Pediatr 2018;116(5):328-332.

\section{INTRODUCTION}

Masked hypertension ( $\mathrm{MH}$ ) in pediatrics is defined by normal office blood pressure (BP) values and high values outside the clinical setting. ${ }^{1} \mathrm{MH}$ may be diagnosed with 24-hour ambulatory BP monitoring (ABPM), which, in addition, may also report other BP patterns (nocturnal hypertension, prehypertension). ${ }^{2}$

$\mathrm{MH}$ is a known, modifiable risk factor for arterial hypertension (HTN), and may potentially damage target organs. ${ }^{3,4}$ The guidelines for $\mathrm{MH}$ diagnosis in children propose BP monitoring with repeated measurements using the auscultatory and oscillometric methods, and 24-hour ABPM.1-3

In our setting, the study of children with risk factors for HTN does not include the systematic use of ABPM. There is evidence to recommend ABPM in the following cases: in children with isolated office BP values greater than the $95^{\text {th }}$ percentile; to diagnose "white coat HTN"; to assess BP patterns and risk for target-organ damage; to assess drug therapy effectiveness; in patients with HTN-associated chronic conditions (overweight/obesity, dyslipemias, diabetes, chronic kidney disease, transplants, neurofibromatosis type I, Turner syndrome, and coarctation of the aorta), and to diagnose $\mathrm{MH}^{5-8}$

According to Lurbe et al., $\mathrm{MH}$ is not an innocent phenomenon, and it is still necessary to gain more knowledge on its clinical significance, adequately identify children at a higher risk, and implement health and / or pharmacological measures aimed at its management. ${ }^{2,4}$

There are not sufficient data on the prevalence of $\mathrm{MH}$ in our population. 


\section{OBJECTIVE}

To estimate the prevalence of $\mathrm{MH}$, isolated nocturnal hypertension (INH), and prehypertension in children who had at least one risk factor for HTN.

\section{MATERIAL AND METHOD \\ Design}

Observational, cross-sectional study with prospective data capture.

\section{POPULATION}

Inclusion criteria

Children aged 5-11 years with normal office $\mathrm{BP}$ and at least one risk factor for HTN, who attended an outpatient visit at Hospital General de Niños "P. de Elizalde" (HGNPE) for a health checkup, were referred to the HTN service between July 1 1, 2015 and December 1 1 1 st, 2016, and gave their informed consent and/or assent were included in consecutive order.

\section{Exclusion criteria}

Patients receiving antihypertensive treatment or those with acute kidney disease were excluded.

\section{Risk factors}

The risk factors for HTN that were considered for inclusion were divided into three categories (neonatal, personal, and family history).

\section{Neonatal history}

- Prematurity: less than 37 weeks of gestational age (any gestational age assessment method).

- Low birth weight (LBW): birth weight $<2500$ grams (term infants).

- History of intrauterine growth restriction (IUGR): birth weight or length $\leq 2$ standard deviations (based on gestational age).

- History of umbilical cord cannulation.

\section{Personal history}

- Isolated high BP (systolic BP and/or diastolic $\mathrm{BP}$ ): greater than the $95^{\text {th }}$ percentile (for height, age, and sex).

- Overweight/obesity: as per the body mass index (BMI). ${ }^{9}$

- Dyslipemia: low density lipoproteincholesterol (LDL) and/or triglycerides $>95^{\text {th }}$ percentile. ${ }^{9}$

- Type I and type II diabetes. ${ }^{10}$

- Chronic steroid administration: more than $1 \mathrm{mg} / \mathrm{kg} /$ day of prednisone per day (or equivalent dosage) for more than 3 weeks. ${ }^{11}$
- Recurrent urinary tract infections: 2 or more in a year.

- Nephropathy or urologic disease: as per nephrological diagnosis.

- Microalbuminuria: $>30 \mathrm{mg} / 24 \mathrm{~h}$ in 24 -hour urine or urinary albumin-to-creatinine ratio $>30 \mathrm{mg} / \mathrm{g}$ or $\mu / \mathrm{mg}{ }^{12}$

- History of hemolytic uremic syndrome.

- Symptoms suggestive of secondary HTN: polyuria, nocturia and / or hematuria.

- Neurofibromatosis type I: confirmed by the dermatology or genetics service.

- Turner syndrome, Williams syndrome.

- Coarctation of the aorta.

- Increased salt (ClNa) intake: defined by the addition of salt to foods, as referred by the child or his/ her caregiver.

- Passive smoking: a family member who smoked at home.

- Sedentary lifestyle: less than 30 minutes of regular exercise per day and less than 3 days a week. ${ }^{13}$

- Renal, abdominal and/or cranial trauma injuries: as documented in the medical record.

- Sleep disorders: nocturnal snoring and/or sleep apnea. ${ }^{2}$

- Seizures of unknown etiology: as documented in the medical record.

\section{Family history of cardiovascular risk (parents,} grandparents or siblings)

- Family HTN.

- Early cardiovascular events $(<55$ years old in males, $<65$ years old in females).

- Type I and type II diabetes mellitus.

- Familial polycystic kidney disease.

\section{Procedure}

Once the informed consent and / or assent was obtained, BP was measured 3 times using the auscultatory method in the upper and lower limbs (Riester sphygmomanometer) and 3 times using the oscillometric method in the upper limbs (Omron 7200). ${ }^{14}$ The first reading was excluded and the second and third ones were averaged for the regression-to-mean effect and patient positioning. All instruments were calibrated regularly. ${ }^{14}$

If normal BP was confirmed with both methods, a 24-hour ABPM with oscillometric method (SpaceLabs 90207/90217, Redmond, Washington) was scheduled. A normal day in terms of school or activities was selected for the ABPM. Readings were scheduled every 20 minutes in the waking state and every 30 minutes during sleep. ${ }^{15}$ 


\section{Outcome measures}

Primary outcome measures

- $\mathrm{MH}$ : it was defined as an average ambulatory systolic BP (SBP) and/or diastolic BP (DBP) value during the day or while doing an activity greater than the $95^{\text {th }}$ percentile by sex and height. Categorical outcome measure. ${ }^{2,16}$ Other possible ABPM results that did not match $\mathrm{MH}$ diagnosis ${ }^{2}$ were considered secondary outcome measures:

- INH: it was defined as an average ambulatory BP during the day or while doing an activity below the $95^{\text {th }}$ percentile and nighttime values greater than the 95th percentile by sex and height. Categorical outcome measure., ${ }^{2,17}$

- Prehypertension: it was defined as an average ambulatory SBP and / or DBP below the $95^{\text {th }}$ percentile, with more than $25 \%$ of $\mathrm{BP}$ readings greater than the $95^{\text {th }}$ percentile for each period. Categorical outcome measure. ${ }^{2,17}$

\section{Control outcome measures}

- Decimal age: in years at the time of the ABPM.

- Heart rate: measured by radial pulse palpation over 1 minute.

\section{Statistical analysis}

For the description, absolute numbers and proportions with their corresponding 95\% confidence interval (95\% CI) were used for categorical outcome measures and mean or median with standard deviation or quartiles were used for continuous outcome measures, based on their adjustment or not to normality (Kolmogorov-Smirnov).

The absolute number of patients with $\mathrm{MH}$ (numerator) divided by the total number of screened patients (denominator) multiplied by 100 was used to estimate the prevalence of $\mathrm{MH}$ as a percentage. The same procedure was used to estimate the prevalence of INH and prehypertension. All values were expressed with their $95 \%$ CI.

The SPSS 10.0 software was used for analysis.

\section{Sample size}

The sample size was calculated to estimate an expected $10 \pm 5 \%$ prevalence of $\mathrm{MH}$ with a $95 \%$ $\mathrm{CI}$, together with a $10 \%$ for failure in adherence; a sample of 110 patients was therefore necessary (StatCalc, Epi Info 7 CDC).

\section{Ethical considerations}

The study followed the Good Clinical Practice Guidelines (guidelines for facilities that are part of the Government of the Autonomous City of Buenos Aires). The Teaching and Research Committee and the Research Ethics Committee of HGNPE authorized the study. ${ }^{18}$ Data confidentiality was warranted and an informed consent and assent were obtained in all cases. Patients with alterations in the ABPM were referred to the HTN service for BP management.

\section{RESULTS}

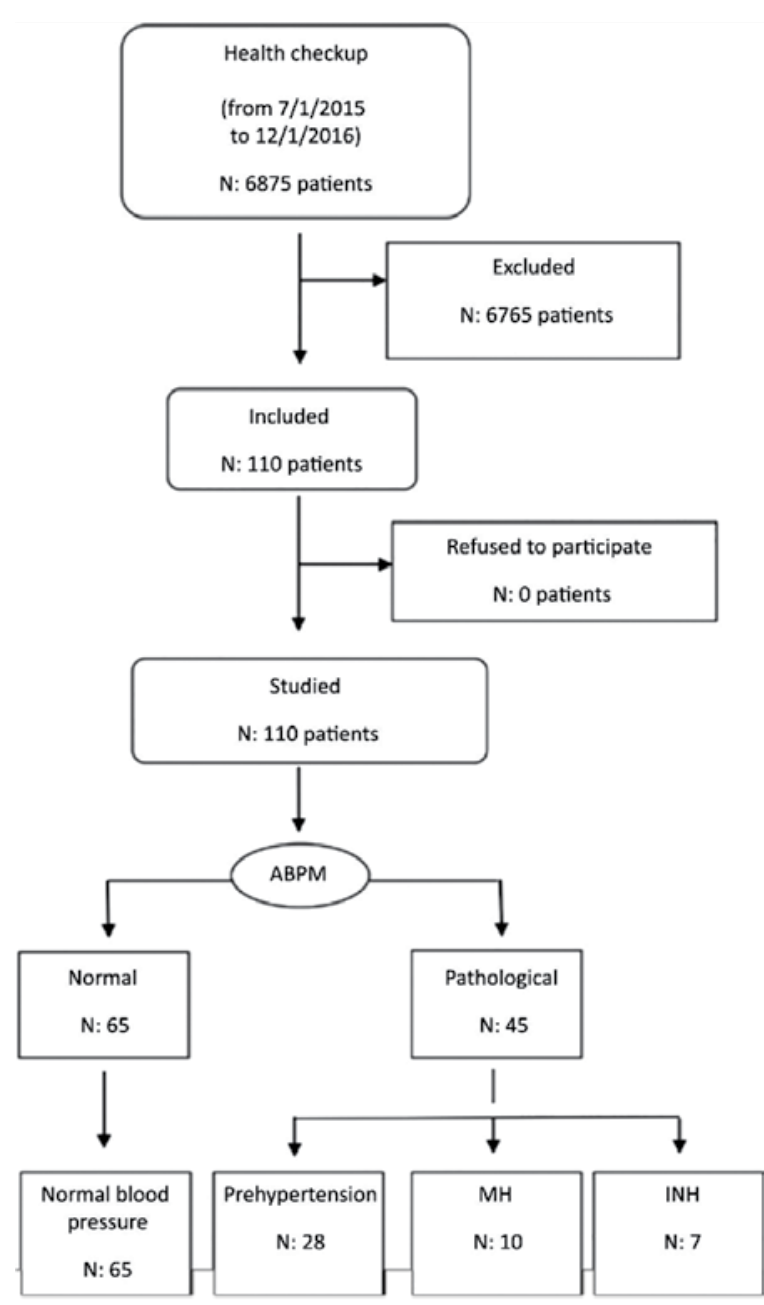

ABPM: 24-hour ambulatory blood pressure monitoring. MH: masked hypertension.

INH: isolated nocturnal hypertension.

\section{General diagram of the study}

Among the 110 patients who entered the study (all patients assessed and no missing data), their average age was $8.74 \pm 1.8$ years, and 60 were girls 
(Table 1 of the Annex).

Neonatal history, personal risk factors, and family history are summarized in Table 1 of the Annex. Twenty-three patients had neonatal history; all had at least one factor corresponding to personal history and $101 \mathrm{had}$ at least one factor corresponding to family history. Considering a pool of the 3 types of history (neonatal, personal, and family), 65 patients had between 7 and 10 factors overall, whereas 12 had 11 or more factors.

The ABPM was done in the 110 participants and helped to identify 10 patients with $\mathrm{MH}$, with a prevalence of $9.1 \%$ (95\% CI: 5.1-15.98\%). In addition, 7 patients had INH $(6.4 \%$; $95 \%$ CI: $3.1-23.5 \%)$, and 28 patients were diagnosed with prehypertension $(25.4 \%$; $95 \%$ CI: $18.2-34.3 \%)$. $A B P M$ recording times, the number of daily readings, and results are shown in Table 2 of the Annex.

The analysis of patients with $\mathrm{MH}(\mathrm{n}=10)$ showed that 7 boys and 9 obese or overweight patients had at least one factor corresponding to family history. The average 24-hour, daytime, and nighttime SBP, DBP, and mean blood pressure $(\mathrm{MBP})$ values (ABPM) of patients with $\mathrm{MH}$ were higher than those of patients with a normal ABPM.

A total of 45 patients had a pathological ABPM $(\mathrm{MH}=10, \mathrm{INH}=7$, and prehypertension $=28)$; the rest $(n=65)$ were considered to have a normal ABPM. Office BP controls using the auscultatory and oscillometric methods and the average 24-hour, daytime, and nighttime SBP, DBP, and MBP values (ABPM) of patients with a pathological ABPM were higher than those of patients with a normal ABPM (Table 3 of the Annex).

\section{DISCUSSION}

In this study, the prevalence values of $\mathrm{MH}$, INH and prehypertension were $9.1 \%, 6.4 \%$, and $25.4 \%$, respectively.

The prevalence of $\mathrm{MH}$ observed here was similar to that reported globally, which estimated a $10-15 \% \mathrm{MH}$ prevalence among pediatric patients. ${ }^{3,4}$ In 2004, Matsuoka and Awazu reported an $11 \%$ prevalence of $\mathrm{MH}$ among children; however, that study included patients aged 6-25 years. ${ }^{19}$ Our sample included younger patients (5-11 years old), which may account for the lower prevalence observed here, which was closer to the prevalence reported in other studies conducted in children and adolescents, with a rate from $7.6 \%$ to $9.4 \% .^{4}$ This is also supported by other publications that found a lower $\mathrm{MH}$ prevalence among younger children. ${ }^{20,21}$

The average ambulatory SBP and/or DBP values recorded during daytime or while doing activities greater than the $95^{\text {th }}$ percentile for sex and height was established as the cut-off point for $\mathrm{MH}$, according to the ABPM reference standard values in pediatrics recommended by a German Task Force based on a multicenter study. ${ }^{17,21}$ Such strict rule to consider MH may have also affected our $\mathrm{MH}$ prevalence.

In relation to the risk factors for $\mathrm{HTN}$, the most common ones were increased salt intake and obesity. The bibliography showed that male sex and obesity were risk factors for $\mathrm{MH} .{ }^{22} \mathrm{An}$ association with male sex was not confirmed. Although most patients with MH had a high BMI, the small number of observations prevented us from confirming such associations.

Lurbe et al. demonstrated significantly higher office SBP and DBP values among patients with MH. ${ }^{4}$ In our study, no significant differences were observed in the average office SBP and DBP values between patients with and without $\mathrm{MH}$. ABPM recordings were significantly higher in the $\mathrm{MH}$ group, thus demonstrating the usefulness of ABPM to unmask HTN in children with risk factors for HTN. ${ }^{4}$

As part of the study's secondary outcomes, we found patients with INH; this finding is of prognostic value. ${ }^{23}$ Some authors consider it is as relevant as daytime HTN and should be considered $\mathrm{MH}$ because it is associated with microalbuminuria and has demonstrated a more rapid progression to chronic kidney failure..$^{15}$ In relation to prehypertension, further studies are required to assess its predictive value for targetorgan damage. ${ }^{15,17}$

This study has potential weaknesses that should be taken into consideration. It was not designed to establish risk factors but to estimate the prevalence of $\mathrm{MH}$. Therefore, the number of patients with $\mathrm{MH}$ prevented us from performing an analysis of inference that would allow to observe statistically significant results (type II error).

The study's prospective design enabled an adequate control of the study outcome measure, which prevented potential biases. In addition, we implemented a strict criterion for patient entry, which included 4-limb BP measurement using 2 different methods 3 consecutive times. Lastly, the implementation of the ABPM showed acceptable 
values in relation to the number of hours it was used and the number of readings, which indicated an adequate result consistency.

\section{CONCLUSION}

In the studied sample, the prevalence of $\mathrm{MH}$ in children who had at least one risk factor for HTN was slightly below $10 \%$.

In addition, the prevalence of INH was $6.4 \%$ and that of prehypertension, $25.4 \%$.

Further studies are required to confirm these results.

\section{REFERENCES}

1. FlynnJT, DanielsSR, Hayman LL, etal.Update:Ambulatory Blood Pressure Monitoring in Children and Adolescents: A Scientific Statement from the American Heart Association. Hypertension 2014; 63(5):1116-35.

2. Lurbe E, Agabiti-Rosei E, Cruickshank JK, et al. 2016 European Society of Hypertension guidelines for the management of high blood pressure in children and adolescents. J Hypertens 2016; 34(10):1887-920.

3. Lurbe E, Cifkova R, Cruickshank JK, et al. Management of high blood pressure in children and adolescents: recommendations of the European Society of Hypertension. J Hypertens 2009; 27(9):1719-42.

4. Lurbe E, Torro I, Alvarez V, et al. Prevalence, persistence and clinical significance of Masked Hypertension in youth. Hypertension 2005; 45(4):493-8.

5. Lurbe E, Torró MI, Alvarez J. Ambulatory blood pressure monitoring in children and adolescents: coming of age? Curr Hypertens Rep 2013; 15(3):143-9.

6. O'Brien E. Unmasking Hypertension. Hypertension 2005; 45(4):481-2.

7. Deregibus M, Haag D, Ferrario C, et al. Consenso sobre Factores de Riesgo de Enfermedad Cardiovascular en Pediatría. Hipertensión Arterial en el Niñoy el Adolescente. Arch Argent Pediatr 2005; 103(4):348-57.

8. Pickering TG, Eguchi K, Kario K. Masked Hypertension: A Review. Hypertens Res 2007; 30(6):479-88.

9. Comité Nacional de Nutrición. Guías de práctica clínica para la prevención, el diagnóstico y el tratamiento de la obesidad. Arch Argent Pediatr 2011; 109(3):256-66.

10. American Diabetes association. Standards of medical care in diabetes 2016. Diabetes Care 2016; 39(Suppl 1):S54-5.

11. Galofré JC. Manejo de los corticoides en la práctica clínica. Rev Med Univ Navarra 2009; 53(1):9-18.

12. Remuzzi G, Schieppati A, Ruggenenti P. Clinical practice. Nephropathy in patients with type 2 diabetes. NEngl JMed
2002; 346(15):1145-51.

13. Comité Nacional de Medicina del Deporte Infanto-Juvenil, Subcomisión de Epidemiología. Consenso sobre factores de riesgo de enfermedad cardiovascular en pediatría. Sedentarismo. Arch Argent Pediatr 2005; 103(5):450-75.

14. Grupo de Trabajo del Programa de Educación Nacional de presión arterial alta en la presión arterial alta en niños y adolescentes de los EE. UU. Cuarto informe sobre el Diagnóstico, Evaluación y Tratamiento de la Hipertensión Arterial en Niños y Adolescentes. Pediatrics 2004; 114(2 Suppl 4th Report):555-76.

15. Barochiner J, Bendersky M, Cuffaro P, et al. Toma de posición, medición de la presión arterial fuera del consultorio: MAPA - MDPA. Sociedad Argentina de Hipertensión Arterial. 2014. [Accessed on: April 27th, 2018]. Available at: www.saha.org.ar/pdf/formacion/ TomaDePosicion-Libro2015.pdf.

16. Soergel M, Kirschstein M, Busch C, et al. Oscillometric twenty-four hour ambulatory blood pressure values in healthy children and adolescents: A multicenter trial including 1141 subjects. J Pediatr 1997; 130(2):178-84.

17. Wühl E, Witte K, Soergel M, et al. Distribution of 24-h ambulatory blood pressure in children: normalized reference values and role of body dimensions. J Hypertens 2002; 20(10):1995-2007.

18. Argentina. Ministerio de Salud. Guía de las Buenas Prácticas de Investigación Clínica en Seres Humanos. Resolución 1490/2007. [Accessed on:December 10th, 2014]. Available at: http://www.fbioyf.unr.edu.ar/evirtual/ $\mathrm{mod} /$ resource $/$ view.php?id=1129\&redirect $=1$.

19. Matsuoka S, Awazu M. Masked hypertension in children and young adults. Pediatr Nephrol 2004; 19(6):651-4.

20. Lurbe E, Sorof JM, Daniels SR. Clinical and research aspects of ambulatory blood pressure monitoring in children. J Pediatr 2004; 144(1):7-16.

21. Urbina E, Alpert B, Flynn J, et al. Ambulatory blood pressure monitoring in children and adolescents: recommendations for standard assessment: a scientific statement from the American Heart Association Atherosclerosis, Hypertension, and Obesity in Youth Committee of the council on cardiovascular disease in the young and the council for high blood pressure research. Hypertension 2008; 52(3):433-51.

22. Álvarez Pitti J. Significado de la hipertensión arterial enmascarada en niños y adolescentes. 2014. [Dissertation]. Valencia: Universidad de Valencia; 2014. [Accessed on: November 24th, 2016]. Available at: https:/ / core.ac.uk/ download/pdf/71027021.pdf.

23. Fan HQ, Li Y, Thijs L, et al. Prognostic value of isolated nocturnal hypertension non ambulatory measurement in 8711 individuals from 10 populations. J Hypertens 2010; 28(10):2036-45. 


\section{Annex}

TABLE 1. Risk factors for arterial hypertension by sex

\begin{tabular}{|c|c|c|c|}
\hline & Boys & Girls & Total \\
\hline $\begin{array}{l}\text { Number of subjects } \\
\text { Age (years) } \\
\text { Z-score for weight* } \\
\text { Z-score for height* } \\
\left.\text { BMI (weight } / \text { height }^{2}\right)^{*} \\
\text { Heart rate }(\mathrm{bpm})^{*}\end{array}$ & $\begin{array}{c}50 \\
8.7 \pm 1.7 \\
2.9 \pm 2.1 \\
2.7 \pm 12.0 \\
23.7 \pm 4.6 \\
90.4 \pm 9.7\end{array}$ & $\begin{array}{c}60 \\
8.7 \pm 1.8 \\
5.4 \pm 26 \\
0.9 \pm 1.0 \\
21.7 \pm 6.2 \\
94.6 \pm 10.2\end{array}$ & $\begin{array}{c}110 \\
8.74 \pm 1.8 \\
2.49 \pm 2.5 \\
1 \pm 0.9 \\
22.6 \pm 5.5 \\
92.7 \pm 10.2\end{array}$ \\
\hline $\begin{array}{l}\text { Neonatal history (n: 23) } \\
\text { Prematurity } \\
\text { Birth weight of less than } 2500 \mathrm{~g} \\
\text { Birth weight }(\mathrm{g})^{*} \\
\text { IUGR } \\
\end{array}$ & $\begin{array}{c}8 \\
6 \\
3241 \pm 0.524 \\
3 \\
\end{array}$ & $\begin{array}{c}11 \\
10 \\
3082 \pm 0.488 \\
5 \\
\end{array}$ & $\begin{array}{c}19 \\
16 \\
3154.68 \pm 0.863 \\
8\end{array}$ \\
\hline $\begin{array}{l}\text { Personal history (n: 110) } \\
\text { Increased salt intake } \\
\text { Obesity } \\
\text { Smoking in the household } \\
\text { Chronic corticosteroids } \\
\text { Polyuria/ nocturia/hematuria } \\
\text { Sedentary lifestyle } \\
\text { Dyslipemia } \\
\text { Sleep disorders } \\
\text { Isolated SBP and / or DBP > 95th percentile } \\
\text { Urinary tract infections } \\
\text { Nephropathy } \\
\text { Microalbuminuria } \\
\text { Turner syndrome } \\
\text { Type I and type II diabetes } \\
\text { Seizures of unknown etiology } \\
\text { Trauma injuries } \\
\text { Corrected coarctation of the aorta } \\
\text { HUS }\end{array}$ & $\begin{array}{l}38 \\
42 \\
27 \\
26 \\
17 \\
20 \\
15 \\
20 \\
14 \\
11 \\
5 \\
2 \\
0 \\
1 \\
4 \\
1 \\
2 \\
0 \\
\end{array}$ & $\begin{array}{l}54 \\
39 \\
28 \\
29 \\
22 \\
16 \\
20 \\
19 \\
19 \\
26 \\
6 \\
1 \\
2 \\
1 \\
2 \\
2 \\
0 \\
0\end{array}$ & $\begin{array}{l}92 \\
81 \\
55 \\
55 \\
39 \\
36 \\
35 \\
39 \\
33 \\
37 \\
11 \\
3 \\
2 \\
2 \\
6 \\
3 \\
3 \\
2 \\
0 \\
\end{array}$ \\
\hline $\begin{array}{l}\text { Family history (n: 101) } \\
\text { History of HTN } \\
\text { History of diabetes } \\
\text { History of stroke } \\
\text { Familial polycystic kidney disease }\end{array}$ & $\begin{array}{c}44 \\
31 \\
18 \\
7\end{array}$ & $\begin{array}{l}53 \\
38 \\
20 \\
12\end{array}$ & $\begin{array}{l}97 \\
69 \\
38 \\
19\end{array}$ \\
\hline
\end{tabular}

* Average \pm standard deviation. BMI: body mass index.

IUGR: intrauterine growth restriction.

HUS: hemolytic uremic syndrome.

SBP: systolic blood pressure.

DBP: diastolic blood pressure. 
II / Arch Argent Pediatr 2018;116(5):328-332 / Original article

TABLE 2. Twenty-four hours ambulatory blood pressuremonitoring recordings in children with risk factors for arterial hypertension

\begin{tabular}{|c|c|c|}
\hline Total no. of ABPM & $\mathbf{N}=\mathbf{1 1 0}$ & \\
\hline \multicolumn{3}{|l|}{ Specifications: * } \\
\hline ABPM duration (hours) & $23.18 \pm 1.8$ & \\
\hline Total no. of readings & $53.3 \pm 9.5$ & \\
\hline Total percentage of readings & $83.7 \pm 10.4 \%$ & \\
\hline No. of daytime readings & $36.4 \pm 8.6$ & \\
\hline No. of nighttime readings & $16.9 \pm 5.1$ & \\
\hline Results: $^{*}$ & Systolic BP (mmHg) & Diastolic BP (mmHg) \\
\hline Average 24-hour BP (mmHg) & $109.3 \pm 8.7$ & $65.7 \pm 5.8$ \\
\hline Average daytime BP (mmHg) & $113.2 \pm 8.6$ & $69.4 \pm 6.1$ \\
\hline Average nighttime $\mathrm{BP}(\mathrm{mmHg})$ & $101.8 \pm 8.6$ & $57.5 \pm 5.7$ \\
\hline Mean 24-hour BP (mmHg) & $81.4 \pm 5.8$ & $81.4 \pm 5.8$ \\
\hline Mean daytime BP (mmHg) & $84.9 \pm 6.3$ & $84.9 \pm 6.3$ \\
\hline Mean nighttime $\mathrm{BP}(\mathrm{mmHg})$ & $74.4 \pm 6.1$ & $74.4 \pm 6.1$ \\
\hline \multicolumn{3}{|l|}{ Diagnosis: ** } \\
\hline Normal ABPM & 65 (59.1\%; 95\% CI: 49.7-67.8\%) & \\
\hline Masked hypertension & $10(9.1 \% ; 95 \%$ CI: $5.1-15.98 \%)$ & \\
\hline Isolated nocturnal hypertension & $7(6.4 \% ; 95 \%$ CI: $3.1-23.5 \%)$ & \\
\hline Prehypertension & $28(25.4 \% ; 95 \%$ CI: $18.2-34.3 \%)$ & \\
\hline
\end{tabular}

* Average and standard deviation.

** Prevalence and 95\% confidence interval.

ABPM: 24-hour ambulatory blood pressure monitoring.

BP: blood pressure.

CI: confidence interval. 
TABLE 3: Average blood pressure recordings ${ }^{* *}$ in patients with pathological and normal 24-hour ambulatory blood pressure

\begin{tabular}{lccc}
\hline & Pathological ABPM & Normal ABPM & P value \\
\hline Number & 45 & 65 & NS \\
Sex (male/female) & $21 / 24$ & $29 / 36$ & 0.02 \\
Age (years) & $8.2 \pm 1.7$ & $9.1 \pm 1.8$ & NS \\
Z-score for weight & $2.1 \pm 2.1$ & $2.6 \pm 3.6$ & NS \\
Z-score for height & $2.6 \pm 1.2$ & $1.1 \pm 0.9$ & NS \\
Z-score for BMI & $3.1 \pm 1.1$ & $3.2 \pm 1.2$ & NS \\
ABPM duration (hours) & $22.8 \pm 1.5$ & $23.4 \pm 2.1$ & \\
\hline Office BP (mmHg) & & & 0.06 \\
SBP of the upper limb, auscultatory method & $97.4 \pm 8.7$ & $93.8 \pm 10.5$ & 0.02 \\
DBP of the upper limb, auscultatory method & $59.2 \pm 7.1$ & $55.7 \pm 7.8$ & NS \\
SBP of the lower limb, auscultatory method & $117.5 \pm 9.7$ & $115.9 \pm 12.6$ & NS \\
DBP of the lower limb, auscultatory method & $69.4 \pm 9.3$ & $68.4 \pm 9.5$ & NS \\
SBP, oscillometric method & $103.1 \pm 8.8$ & $101.1 \pm 8.9$ & NS \\
DBP, oscillometric method & $64.6 \pm 8.1$ & $63.9 \pm 7.1$ & $<0.001$ \\
Ambulatory BP (ABPM) (mmHg) & & & $<0.001$ \\
Average 24-hour SBP & $115.8 \pm 6.9$ & $104.7 \pm 6.7$ & $<0.001$ \\
Average 24-hour DBP & $69.6 \pm 5.1$ & $63.1 \pm 4.5$ & $<0.001$ \\
Average 24-hour MBP & $85.9 \pm 5.1$ & $78.3 \pm 3.8$ & $<0.001$ \\
Average daytime SBP & $119.6 \pm 6.9$ & $108.7 \pm 6.6$ & $<0.001$ \\
Average daytime DBP & $73.6 \pm 5.5$ & $66.5 \pm 4.5$ & $<0.001$ \\
Average daytime MBP & $89.6 \pm 5.4$ & $81.7 \pm 4.7$ & $<0.001$ \\
Average nighttime SBP & $108.1 \pm 8.2$ & $97.5 \pm 8.8$ & $<0.001$ \\
Average nighttime DBP & $61.5 \pm 5.7$ & $54.7 \pm 3.7$ & 0.01 \\
Average nighttime MBP & $79.1 \pm 5.8$ & $71.2 \pm 3.6$ & \\
Average 24-hour heart rate & $95.5 \pm 9.7$ & $90.7 \pm 10.1$ &
\end{tabular}

* Average \pm standard deviation.

NS: not significant.

${ }^{* *} t$ test for independent samples; values are expressed as average and standard deviation.

BP: blood pressure.

SBP: systolic blood pressure.

DBP: diastolic blood pressure.

MBP: mean blood pressure.

BMI: body mass index.

ABPM: 24-hour ambulatory blood pressure monitoring. 